\title{
Synthesis of Derivatives of Biogenic Amines Labelled with Radioactive Tracers for Brain Imaging
}

\section{Arturo A. Vitale}

PROPLAME- CONICET, Departamento de Química Orgánica, Facultad de Ciencias Exactas y Naturales, Universidad de Buenos Aires, Pabellón 2, Piso 3, Ciudad Universitaria, 1428 Buenos Aires, Argentina

\begin{abstract}
Endogenous derivatives of biogenic amines, such as phenethylamines, indolalkylamines and harmines, have been extensively studied as usual constituents of body fluids. Methylated derivatives of indolalkylamines have been also related to mental disorders, e.g. schizophrenia and hallucination.
\end{abstract}

In vivo imaging constitutes a powerful tool for the evaluation of the state of the central nervous system (CNS), in particular the brain in normal and altered states due to mental disorders or occurrence of tumors.

SPECT (Single Photon Emission Tomography), and PET (Positron Emission Tomography) are the usual techniques. For SPECT a molecule labelled with a gamma-emissor is required. The label may be incorporated to the molecule either covalently, e. $g$. I-131 or I-125, or by means of the formation of complexes with some gamma-emissor metal, usually Tc-99m owing to its low-energy gammaemission and short half life.

The new methodology developed in our laboratories for the synthesis of labelled molecules to be used with SPECT is to be discussed in this lecture.

Synthetic strategies of molecules belonging to the families of phenethylamines, indolalkylamines and harmanes labelled with I-131 will be described. These preparations involved thalium derivatives as shown in the scheme.<smiles>CCCCCNCCc1cc(C)c(I)c(I)c1</smiles><smiles>CCCCCCCc1cc(N)c(I)c(I)c1CCN</smiles><smiles>CCCc1cc(N)c(F)c(I)c1I</smiles><smiles>Cc1c(I)cc(CCN)c(I)c1I</smiles> 
Preparation of alkylamines labelled with Tc-99m will be also discussed as well as the static biodistribution in laboratory animals.

\section{References}

1. Vitale, A.; Calviño, A. A.; Ferrari, C. C.; Stahl, A.; Pomilio, A. B. Preparation and Biological Evaluation of Tc-99m Phenethylamine Complexes. J. Labelled Compnds. Radiopharm. 1995, 36, 6509.

2. Sintas, J. A.; Vitale, A. A. ${ }^{131}$ I Derivatives of Indolealkylamines for Brain Mapping. J. Labelled Compnds. Radiopharm. 1997, 39, 677.

3. Sintas, J. A.; Vitale, A. A. ${ }^{131}$ I Labelled Phenethylamines for Metabolic Studies J. Labelled Compnds. Radiopharm. 1998, 41, 53.

3. Sintas, J. A.; Vitale, A. A. Synthesis of ${ }^{131}$ I Derivatives of Harmane Alkaloids. J. Labelled Compnds. Radiopharm. 1999, 42, 409-413. 